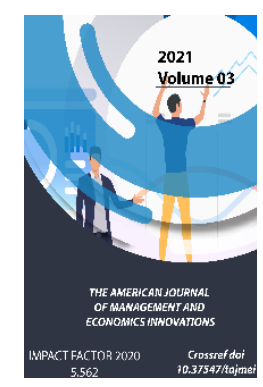

\title{
System Of Indicators Reflecting The Process Of Innovation Transfer In Higher Educational Institutions
}

Urinov Dilshodjon Akhmadjonovich

Researcher, Fergana State University, Uzbekistan

Journal Website:

https://theamericanjou

rnals.com/index.php/ta

jmei

Copyright: Original

content from this work

may be used under the

terms of the creative

commons attributes

4.0 licence.

\section{ABSTRACT}

Technology transfer process plays an important role in the process of increasing the competitive advantage of the enterprises of the country, in the development of the country's economy and as well in implementation of the scientific achievements to the practice. The article lists out system indicators for analysis and rational organization of innovation transfer, on the basis of application of which scientific conclusions and recommendations for further improvement of management of process are provided.

\section{KEYWORDS}

Innovation Transfer, Innovation Transfer Process Management, Innovation Transfer Process Indicators, Patent Application, Patent, License Agreements, Royalties, Start-Up Enterprises.

\section{INTRODUCTION}

In order to ensure sustainable growth of the country's economy, the establishment of modern, high-tech productions for the production of high value-added products competitive in domestic and world markets, ensuring comprehensive and efficient use of production and resource potential. One of the priorities is to attract researchers and talented young people from research institutes, to introduce the results of research into production, to further develop the integration of science, education and industry. Higher educational institutions (HEls) are considered to be the most important structure in ensuring the transition to an innovative approach to sustainable economic growth, and in order to further increase the socio-economic impact of ongoing research achievements, there is a 
need to introduce them into production and further improve their transfer activities. In determining the effectiveness of reforms in this area, various indicators are used, which allow to quantitatively and qualitatively assess the transfer process. The indicators used serve to determine the effectiveness of funds allocated for research, the development of measures related to the implementation of research and the transfer of their results, the establishment of priorities in this area. At the same time, it provides an opportunity to conduct a comparative analysis of institutions operating in the country in the field of innovation transfer, both internally and internationally. A comparative analysis of the indicators of innovation transfer in higher education serves to identify best practices in the field of innovation transfer, their application in other universities and the development of various proposals for further development.

\section{Critical analysis of indicators applied in the} field. Today, different countries use different indicators related to the transfer of innovations. In the analysis of scientific papers on the general indicators of innovation transfer in higher education patent applications, received patents, license agreements, funds from license agreements, spin-off enterprises and indicators related to their activities (cash flow, number of employees and etc.), indicators of innovation transfer offices, funds directed to higher education institutions for research work by manufacturing enterprises, etc., can be seen and are studied in detail. These indicators are used by universities in different countries, as well as by various organizations to collect information on the process of innovation transfer in universities, analyze them and develop proposals to improve this process, comprehensive incentives for stakeholders. Different universities use different indicators in their reports that reflect their innovation transfer processes, and they do so in the way they have developed. It can be seen that there is no clear system of indicators and precise methods of calculating them to reflect the process of innovation transfer worldwide.

A weak point of research in this area is the inaccuracy and incompleteness of innovation indicators and the existence of disputes and controversies in their interpretation and evaluation. Because of this, we have conducted scientific research to overcome this problem. We also tried to calculate the transfer indicators in order to obtain information on the organization of the innovation transfer process in our country, analyze it and develop conclusions and recommendations for improving this process. At the same time, in addition to the existing indicators, new ones were considered, taking into account the opportunities created by the government for the implementation of research results in higher education.

Scientific results obtained and their discussion. The main purpose of the innovation transfer function of universities is the licensing and commercialization of inventions created in these organizations. In this regard, the responsibility of universities is to create conditions for the commercialization of intellectual property (IP) with high potential for commercialization. One of the key indicators in the field of innovation transfer is the number of patent applications to IPs and the number of patents obtained. The number of patent applications or patents obtained for IPs does not mean that their transfer has yet to 
take place. It is necessary to legally protect IPs created by scientists, but having a large number of unlicensed patents does not yet indicate that the innovation transfer process is effectively organized. Nevertheless, this indicator shows that the activity of scientists in the field of research is positive, their inventive activity is supported and the inventive environment is formed. However, the legal protection of high-potential IPS is the first important step for their transfer.

Applying for patents for IPs and obtaining a patent for them usually requires a certain cost. However, HEls at this time will not have a clear idea that the revenue from licensing the right to this patent in the future can cover the costs associated with obtaining a patent. The fact that universities take the risk associated with the protection of intellectual property means that they are ready to transfer these innovations.

The Republican Fair of Innovative Ideas, Technologies and Projects, which has been held in our country since 2008, plays an important role in ensuring further integration between science and industry, establishing cooperation between research institutions and enterprises of the real economy. While the innovations proposed by the universities at the fair do not lead to their direct transfer to production, they do allow for their transfer, such as patents obtained for research results. Therefore, in our country, this indicator can be considered as one of the important indicators reflecting the process of innovation transfer in educational institutions.

The lack of active participation of universities in fairs can be attributed to insufficient organization of research in these educational institutions, their lack of production needs, inefficient organization of incentives for researchers, insufficient formation of the research environment.

The main indicators of the effectiveness of innovation transfers are concluded and completed license agreements and licensing revenues, as well as royalties. License fees and royalties received are important indicators of the commercial viability of inventions. Information on patent applications and the amount of patents issued by national patent offices does not fully reflect the information on the quality of these IPs in a given country.

In assessing the effectiveness of patents, the amount of royalties paid for the use of intellectual property rights is often compared. In the absence of a royalty payment indicator, an indicator of the volume of licensing agreements for the use of patented inventions can be used as an indicator of the effectiveness of patents.

The generalized indicators listed above are insufficient to study the impact of innovation transfer in higher education on the regional economy. Therefore: the share of licenses issued to regional enterprises in the number of issued licenses; the share of income from licenses issued to enterprises of the region in the total income from licensing; the share of licenses issued to start-up enterprises in the region in the total number of issued licenses; indicators such as the number of start-ups established in the region on the basis of knowhow technologies are used.

The issuance of licenses by universities to enterprises in the region where they are located depends largely on external factors such as the economic health of the region, the types of enterprises located in it, the 
infrastructure created to support new businesses in the region.

The share of licensing agreements with regional enterprises in total license agreements shows that research results and IPs have been retained in the economic development of the region for the development of the regional economy. The share of licensing agreements with start-ups is also important in analyzing the role of innovation transfer in the economic development of the region. In some cases, start-ups hire a university inventor as a technical consultant. Therefore, along with the number of start-up enterprises established, the number of employees is also calculated, indicating the amount of new jobs created in these enterprises.

The success of a particular university in licensing activities is limited by the conditions created to support new and growing businesses in the region in which it is located. The lack of interest in the research results of higher education institutions by a small number of enterprises, the poor development of business support infrastructure is among the factors hindering the possibility of transfer processes.

One of the technical support areas of the innovation transfer process is the use of the services of university staff or research laboratory equipment at the disposal of universities to conduct tests and evaluations in order to answer relatively narrow, well-formed questions and problems. Therefore, the number of departments, research laboratories of universities established in manufacturing enterprises can also be considered as transfer indicators.
Another indicator of the transfer of innovations is the number of scientific articles published in collaboration with manufacturing companies and universities. This figure may not fully reflect the transfer process. However, it can be used as an indicator of research cooperation between universities and manufacturing enterprises.

\section{CONCLUSIONS AND RECOMMMNDATIONS}

The indicators used by universities to describe the process of innovation transfer do not allow to fully cover and evaluate this process. They can only reflect some aspects of the transfer process. However, quantitative indicators do not directly represent the qualitative indicators of this process. The determined amount of this or that indicator may not be able to assess future results, reflecting the current situation. The main purpose of the calculation and analysis of indicators reflecting the process of innovation transfer should be to make management decisions related to further improvement of innovation transfer in higher education. Unless these indicators are linked to decision-making, these indicators will remain information only.

The following recommendations can be made to further improve the process of innovation transfer in the universities of our country:

1. Formation of a system of strictly defined indicators reflecting the activity of innovation transfer in higher education, improvement of existing ones in accordance with international standards. On the basis of comparative analysis of indicators to identify best practices, strategies, policies and programs in the field of innovation transfer of universities operating effectively in this area, their 
application in other institutions, the development of various proposals for its further development;

2. Expenses incurred for research activities and income from the transfer of its results, their distribution by areas should be specified separately. It is also necessary to reflect the distribution of the results by areas (medical, social, construction, etc.);

3. It is necessary to establish a practice of posting in the prescribed form reports of all institutions on the results of innovation transfer activities on their websites. This will help manufacturing enterprises to create a database on the innovative potential of institutions, further development of research cooperation between universities and manufacturing enterprises, the formation of a real demand for innovation;

4. Transparency of information on projects implemented at the expense of allocated funds for the effective use of budget funds should be ensured. This information will serve for the decision-making process on which areas the funds should be directed in the future, and how they can be used effectively. Strengthening the requirements for reporting on the work done in the framework of ongoing fundamental, practical and innovative projects will motivate the project implementers to more effectively carry out the work identified under the project.

5. It is necessary to create a database of indicators and indicators that reflect the impact of research on the regional level, ie the city, district, region, republic, international level, where the university is located.

\section{REFERENCES}

1. Resolution of the President of the Republic of Uzbekistan dated July 15, 2008 No PF916 "On additional measures to encourage the introduction of innovative projects and technologies in production" (source: www.uzscience.uz/images/norm.acts/PP916.doc).

2. Peregudov L.V., Saidov M.X. Higher education management and economics. $\mathrm{T}$ : Finance, 2002.

3. Magnus Gulbrandsen and Einar Rasmussen. Indicators for the commercialization of research: what do they tell us? The case of Norway.

[Electronic source] http://www.primenoe.org/spip.php?action=acceder_docume nt\&arg=458\&cle=bea0 508 eo 8 a39326doc 1 4caood3d7aa6b5ed5aeb\&file=pdf\%2Fgulbr andsen.pdf

4. Darrell M. West. Improving University Technology Transfer and Commercialization. [Electronic source] http://www.insidepolitics.org/brookingsre ports/University_Tech_Transfer.pdf

5. Approach to the efficiency of technology transfer. Informatsionno-analiticheskie materials. Nizhny Novgorod. 2011. [Electronic source] http://www.int.unn.ru/files/2013/08/09.pdf 